\title{
LOS BOLETINES ECLESIÁSTICOS COMO FUENTE PARA LA HISTORIA DE LA ENSEÑANZA PRIMARIA EN ESPAÑA
}

\author{
$(1851-1931)^{\alpha}$
}

\section{Ecclesiastical bulletins as a source for the history of primary education in Spain (1851-1931)}

\section{Carmen Diego Pérez ${ }^{\circledR}$ y Montserrat González Fernández}

Fecha de recepción: 26/07/2018 • Fecha de aceptación: 05/01/2019

Resumen. Recurrir a publicaciones periódicas en la investigación histórica es habitual desde las últimas décadas; sin embargo, la información proporcionada por los boletines eclesiásticos —órganos de difusión de las directrices oficiales de la Iglesia católica - no ha sido suficientemente utilizada para conocer las conexiones y relaciones entre la Iglesia católica y el estado en torno a la enseñanza. Este artículo tiene el objetivo de señalar las potencialidades de estos boletines para los historiadores de la educación. En este sentido sintetizamos, en primer lugar, el marco legal y la doctrina de dicha iglesia — desde el nacimiento de esta publicación periódica a mediados del siglo XIX hasta la tercera década del siglo $\mathrm{XX}$ - y esbozamos la relación que mantuvieron iglesia y estado durante este periodo. A continuación, caracterizamos los boletines eclesiásticos y apuntamos aquellas cuestiones educativas relativas a la enseñanza primaria que tratan y que servirían, en unos casos, para contrastar y comparar informaciones procedentes de otras fuentes —el control que la Iglesia católica y el estado ejercieron sobre el magisterio en relación con las

\footnotetext{
a Este trabajo forma parte de la investigación El estado y la iglesia como órganos de control del profesorado no universitario. España. 1857-1931, Proyecto I+D EDU2014-53679 financiado en el marco del Programa Estatal de Fomento de la Investigación Científica y Técnica de Excelencia. Subprograma estatal de generación de conocimiento del Ministerio de Economía y Competitividad, coordinado por Isabel Grana Gil y Francisco Martín Zúñiga.

в Departamento de Ciencias de la Educación, Facultad de Formación del Profesorado y Educación. C/ Aniceto Sela s/n. 33005 Oviedo, España. cdiego@uniovi.es (D) https://orcid.org/000-0002-4746-2670

v Departamento de Ciencias de la Educación, Facultad de Formación del Profesorado y Educación. C/ Aniceto Sela s/n. 33005 Oviedo, España. montseg@uniovi.es (D) https://orcid.org/0000-0002-6790-347X
} 
prácticas religiosas que debían realizar con los escolares, por ejemplo$\mathrm{y}$, en otros, para investigar aspectos poco conocidos —el asociacionismo del magisterio católico, es otro ejemplo-, contribuyendo, así, a la construcción de una historia de la educación primaria oficial más completa.

Palabras clave: Iglesia católica; Control; Enseñanza; Publicación periódica; España.

Abstract. Resorting to periodic publications in historical research has become common in recent decades; however, the information supplied by ecclesiastical bulletins - the broadcasting organ of the Catholic Church's official directives - has not been used sufficiently as a tool for understanding the connections and relationships between the church and the state as regards teaching. This article aims to point out the potential that these bulletins have for education historians. In this regard, we first set out to synthesize the legal framework and the church's doctrine - beginning with the birth of the periodic publication in the mid-19th century up to the third decadfe of the 20th century - and we outline the relationship that church and state maintained during this period. Then we characterize the ecclesiastical bulletins and take note of those educational issues related to primary education that are addressed in them and that would be useful, in some cases, to contrast and compare information that comes from other sources - the control that church and state exerted on the teachers in relation to the catholic practices that they should conduct with the students, for example - and, in others, to investigate little known aspects - the catholic teachers' group of associations, as another example-, contributing, thus, to the construction of a more complete history of primary education.

Keywords: Catholic church; Control; Teaching; Periodic publication; Spain.

\section{PRESENTACIÓN}

La necesidad de los obispos de comunicarse fácilmente con arciprestes y sacerdotes de su diócesis les indujo, a mediados del siglo XIX, a poner en marcha una publicación periódica — similar a otras oficiales ya existentes de carácter civil o militar - que les facilitara transmitir la información, naciendo así los boletines eclesiásticos que, entre otras cuestiones, incluyeron las educativas.

Nuestro interés por estos boletines surgió a raíz de un proyecto $\mathrm{I}+\mathrm{D}$ dedicado a investigar «El estado y la iglesia como órganos de control del profesorado no universitario. España 1857-1931»; dentro del grupo de 
investigación nuestro cometido fue indagar, especialmente, sobre encuentros y controversias de la Iglesia católica con el estado relativos a la enseñanza primaria pública, así como las relaciones entre párrocos y maestros, para poder identificar el control y la función supervisora que la iglesia ejerció sobre el magisterio y la escuela. ${ }^{1}$ En este proceso de búsqueda, y tras la consulta de los boletines de trece diócesis publicados entre 1852 y 1931, hemos podido comprobar que aportan información sustantiva para documentar otros aspectos educativos - algunos poco conocidos-, por lo que este trabajo tiene como objetivo divulgar la potencialidad de esta fuente para contrastar hechos e ideas.

No obstante, no estamos ante una fuente desconocida para los historiadores que la han utilizado bien para estudiar aspectos concretos en una diócesis como el conflicto de las desamortizaciones o la economía, ${ }^{2}$ la aprobación o rechazo de libros, ${ }^{3}$ el análisis de la información difundi$\mathrm{da}^{4} \mathrm{o}$ bien, utilizando boletines de cuatro diócesis para estudiar la figura

\footnotetext{
1 Comenzamos a indagar en esta fuente al observar que la documentación administrativa generada por las Juntas locales de instrucción primaria -órganos que iniciarían el proceso de control del magisterio- es ingente, está excesivamente dispersa y hace que la tarea sea inabarcable, lo que unido a los avatares de los archivos municipales y la escasa atención que reciben en la actualidad — sin archivero, sin instrumentos de descripción, etc.- dificulta la identificación y el acceso a esa información.

2 Es el caso de la tesina de Sandra de Pablo Hervás, «El conflicto de las desamortizaciones en el Boletín Eclesiástico del Obispado de Osma», presentada en la Universidad Pontificia de Salamanca, 2000, o la investigación de Jesús María Palomares, «La economía de la iglesia española. El caso de la diócesis de Osma (1851-1936)», Investigaciones históricas. Época moderna y contemporánea 19 (1999): 103-123.

3 Abordado en los trabajos de Leandro Higueruela Pino, quien identifica los aparecidos entre 1836 y 1968 en los siguientes artículos publicados en Hispania Sacra. Revista de Historia eclesiástica de España: «En torno a la bibliografía del Boletín Eclesiástico de la diócesis de Toledo en el siglo XIX» 31, no. 61 (1978): 571-667; 34, no. 70 (1982): 551-666; 35, no. 71 (1983): 317-367; 40, no. 81 (1988): 469538; 42, no. 85 (1990): 113-166; 43, no. 87 (1991): 121-152, y 44, no. 89 (1992): 249-287; Antón M. Pazos, «Lectura y religión en Navarra: libros sobre espiritualidad difundidos a través del Boletín Oficial Eclesiástico (1900-1930)», Hispania sacra 56, no. 114 (2004): 741-772, o del mismo autor «El párroco eficaz. Técnica parroquial y mentalidad eclesiástica en la bibliografía recomendada por el Boletín de Pamplona (1900-1930)», Hispania sacra 57, no. 116 (2005): 709-744, donde recoge las publicaciones con orientaciones pedagógicas al clero para la catequesis de los niños, así como los textos de catecismo recomendados y otros medios pedagógicos como las estampas de la editorial barcelonesa Luis Gili o la colección España y su historia de la editorial Calleja.

${ }_{4}$ Pilar Salomón Chéliz, «Mucho más que religión: Contenidos de la prensa eclesiástica oficial: el Boletín Eclesiástico Oficial del Arzobispado de Zaragoza (1900-1936)", en Prensa y periodismo especializado: historia y realidad actual: I congreso de prensa y periodismo especializado, eds. Juan José Fernández Sanz, José Carlos Rueda Laffond y Carlos Sanz Establés (Guadalajara: Ayuntamiento de Guadalajara, 2002), 193-208.
} 
de Pio XI. ${ }^{5}$ Asimismo, los historiadores de la educación también la han utilizado, pero ocasionalmente, para ilustrar diferentes aspectos de la educación española contemporánea: la secularización, ${ }^{6}$ la situación de la enseñanza en una diócesis concreta ${ }^{7} \mathrm{o}$, combinada con otra documentación inédita, la actuación educativa de la Iglesia católica. ${ }^{8}$ No estamos, pues, ante una fuente olvidada ${ }^{9}$ pero sí, posiblemente, ante una documentación infrautilizada; por tanto, el objetivo de este artículo es apuntar las potencialidades y prestaciones que los boletines eclesiásticos pueden aportar a los historiadores de la educación.

Consideramos que estos boletines son una fuente de información apropiada y fiable para conocer el pensamiento y actuación de la Iglesia católica al proporcionar los discursos, las prácticas y los hechos relevantes en torno a su misión educadora, permitiendo trabajar la dimensión interpretativa al poder cotejar y contrastar su información con la suministrada por otras fuentes. Estos boletines recogen las intervenciones de los obispos en sus respectivas diócesis, sus directrices sobre educación, su sistemático recuerdo de la legislación que favorecía a la Iglesia católica en cuestiones

\footnotetext{
${ }_{5}^{5}$ Javier Marín-Porgueres, «La recepción en España del Magisterio de Pío XI sobre la Santidad. Un estudio desde los Boletines Eclesiásticos», Cuadernos doctorales: teología (Excerpta e dissertationibus in Sacra Theologia) 60 (2013): 475-563.

6 Teódulo García Regidor, La polémica sobre la secularización de la enseñanza en España (1902-1914) (Madrid: Fundación Santa María, 1985).

${ }^{7}$ Francisco Martín Zúñiga, «La lucha contra la secularización de la enseñanza en las primeras décadas del siglo XX (1900-1930) vista desde el Boletín Oficial del Obispado de Málaga», Puerta Nueva. Revista de Educación 17 (1993): 61-70, y Ángel Serafín Porto Ucha, «La postura de la iglesia gallega ante el tema de la enseñanza a través de los boletines eclesiásticos durante la Restauración», en Iglesia y educación en España. Perspectivas históricas. IV Coloquio de Historia de la Educación. Palma septiembre 1986. (Palma de Mallorca: Universitat de les Illes Balears. Sección de Historia de la Educación de la S.E.P., 1986), t. I, 255-263.

${ }^{8}$ De este tipo son los trabajos de Francisco Martín Hernández, «La actitud del episcopado», en Historia de la educación en España y América. La educación en la España contemporánea (1789-1975), coord. Buenaventura Delgado Criado (Madrid: Fundación Santamaría-Ediciones SM, 1994), 560568; Bernabé Bartolomé Martínez (dir.), Historia de la acción educadora de la Iglesia en España (Madrid: Biblioteca de Autores Cristianos, 1997), y Miguel-Ángel Hernández Fuentes, «"Educar cristianamente a los obreros". Actividad educativa en la diócesis de Zamora durante la Restauración: las escuelas de adultos y el círculo católico de obreros», Historia de la Educación. Revista Interuniversitaria 36 (2017): 253-256.

${ }_{9}$ Las publicaciones oficiales fueron habitualmente utilizadas por los historiadores y, desde 1973, fecha en que Manuel Tuñón de Lara llamó la atención —en Metodología de la historia social de España (Madrid: Siglo XXI de España)—, sobre las publicaciones periódicas no oficiales, ambas son fuentes favoritas para los historiadores; sin embargo, los boletines eclesiásticos, teniendo esa doble cualidad, fueron escasamente explorados.
} 
de enseñanza, y su denuncia y lamento cuando los políticos tomaban un rumbo diferente al que esperaban. Cada obispo difundió sus cartas pastorales, versando las de algunas diócesis sobre la escuela neutra —en varios boletines de 1908-, el laicismo en la enseñanza — abordado especialmente durante los años 1914 y 1915-, sobre la visita del párroco a las escuelas en 1920, o la enseñanza de la religión en las escuelas normales para la formación del magisterio primario. En definitiva, los obispos utilizaron las páginas del boletín de su diócesis para intervenir en las cuestiones educativas.

\section{MARCO POLÍTICO Y RELIGIOSO}

La información a la que aludiremos en las siguientes páginas abarca un intervalo temporal de ochenta años, los que median entre 1851 y 1931. En este periodo, tanto la actuación de la Iglesia católica como la del estado se modificaron al compás de diversos acontecimientos no solo nacionales sino también internacionales. Así, el contexto político español fue variando al estar marcado por tres constituciones: la de 1845 , que contempló la confesionalidad del estado; la de 1869, que declaró la libertad de culto y la de 1876 con un artículo, el 11, de buscada ambivalencia al declarar la confesionalidad del estado al tiempo que admitía otros cultos. El final del intervalo de estudio, 1931, fue el año de entrada en vigor de una nueva Constitución menos favorable para la Iglesia católica, que declaró, en el artículo 3, que el estado español no tenía religión oficial y en el 48, «que la enseñanza será laica [...]. Se reconoce a las Iglesias el derecho, sujeto a inspección del Estado, de enseñar sus respectivas doctrinas en sus propios establecimientos».

En cuanto al ámbito religioso, desde 1851 hasta mediado el siglo XX, estuvo en vigor el Concordato que Pío IX e Isabel II firmaron el 16 de marzo de aquel año, y que concedió a la iglesia los derechos y capacidades de control de los libros de texto y del profesorado en el ejercicio de la tarea docente. Además de este acuerdo, la doctrina de la Iglesia católica fue desarrollada en algunas encíclicas en las que los pontífices expusieron la doctrina católica sobre algún asunto, condenando errores o resolviendo alguna cuestión de capital importancia; en algunas abordaron la educación de los jóvenes exclusivamente y otras también tuvieron repercusiones en la escuela. A este respecto son significativas Quanta cura de 1864, Acervo nimis de 1905, y Divini illius magistri de 1929. 
Las prerrogativas de la Iglesia católica quedaron reflejadas en estos boletines a través de la actuación de los obispos, quienes mantuvieron la unidad doctrinal señalada desde Roma en cuanto a las cuestiones de educación, expresando «su voz, uno a uno, en perfecta sintonía de razones y de argumentos». ${ }^{10}$ Esta fuente recoge el mayor protagonismo de algunos obispos, ${ }^{11}$ reforzado por el hecho de haber ocupado unos el cargo de senadores, interviniendo directamente en los asuntos de la política, mientras que otros formaron parte del Consejo de Instrucción Pública informando y opinando sobre las cuestiones sometidas a dictamen de este órgano consultivo - entre otras, la aprobación de los libros de texto y las sanciones al magisterio primario. En esta publicación también se aprecia otra estrategia colectiva desarrollada por algunos obispos que tomaron iniciativas inter-diocesanas de opinión y protesta contra el gobierno por las decisiones que podían suponer una pérdida del poder eclesiástico en la enseñanza o la disminución del carácter católico de la sociedad.

Los privilegios concedidos en materia de educación en el Concordato quedaron recogidos en la longeva Ley Moyano al incorporar los derechos de la Iglesia católica a inspeccionar tanto los establecimientos públicos como los privados para «velar sobre la pureza de la doctrina, de la Fe y de las costumbres, y sobre la educación religiosa de la juventud» (artículo 295), y supervisar los libros de texto y las explicaciones de los profesores para evitar que «emitan doctrinas perjudiciales a la buena educación religiosa de la juventud» (artículo 296). Si un prelado detectaba algo sospechoso debía dar «cuenta al Gobierno; quien instruirá el oportuno expediente, oyendo al Real Consejo de Instrucción Pública, y consultando, si lo creyere necesario, a otros Prelados y al Consejo Real» (artículo 296), quedando casi literalmente recogidos los dos primeros artículos del citado Concordato. En cuanto a la enseñanza primaria, su artículo 11 especifica expresamente que «el Gobierno procurará que los respectivos $\mathrm{Cu}$ ras párrocos tengan repasos de Doctrina y Moral cristiana para los niños de las Escuelas elementales, lo menos una vez cada semana».

\footnotetext{
10 Martín Hernández, «La actitud del episcopado», 562.

11 Un caso es el obispo de Tarazona, Cosme Marodán y su conocida carta a la reina quejándose y reclamando los derechos de la iglesia, lo que provocó la aprobación de la Real Orden de 27 de octubre de 1864. En ella se dieron directrices sobre los tres niveles de enseñanza. En relación con el primer nivel se intentó reforzar la colaboración entre los párrocos y el magisterio primario. Este obispo años después sería senador.
} 
Presentado someramente el marco legal político-religioso de la época, a continuación, procedemos a una caracterización de esta fuente primaria de información, que nos permite acercarnos al pensamiento oficial y a la actuación de la Iglesia católica en un período en que defendió su derecho a estar presente en la enseñanza pública cuando iniciaba su andadura el sistema educativo español y también mientras éste se consolidaba, defendiendo su posición con diversas estrategias.

\section{CARACTERIZACIÓN DE LOS BOLETINES ECLESIÁSTICOS}

Cuando apareció el primer boletín eclesiástico —el de la diócesis de Toledo en 1844-, hacía unos años que existían en nuestro país publicaciones periódicas oficiales de carácter civil, al haber promovido la Real Orden de 20 de abril de 1833 la publicación de boletines oficiales por provincias en los que los obispos podían difundir gratuitamente sus documentos oficiales; sin embargo, pronto se animaron a implantar una publicación similar en sus diócesis de modo análogo al que, «bien sea oficial, bien privadamente, se ven puestos en uso por la Administración civil y militar en sus diversos ramos», 12 tal y como expresaba el obispo de Plasencia, quien apoyándose en la Ley de imprenta vigente, se acogió a las prerrogativas que esta otorgaba a la Gaceta de Madrid y a los escritos de otras autoridades reconocidas. Tras algún conflicto entre el poder eclesiástico y el civil, el estado consideró publicaciones oficiales a estos boletines en una circular de $1862 .{ }^{13}$ En ella, la reina recordaba encarecidamente a los prelados que no se diera en sus páginas

cabida a polémica ni a inserción de artículos que directa o indirectamente versen sobre política $\mathrm{u}$ otros objetos distintos de su especialidad, por los conflictos y dificultades que el hacer lo contrario puede engendrar, con detrimento de los verdaderos intereses de la Iglesia y el menoscabo del prestigio del episcopado, que tanto interesa conservar en una esfera superior al campo de las agitaciones de partido. ${ }^{14}$

\footnotetext{
12 "Circular», Boletín Eclesiástico de Obispado de Plasencia 1 (5 de marzo de 1859): 2.

13 Véase dicha circular del Ministerio de Gracia y Justicia en el Boletín Eclesiástico del Obispado de Osma 68 (10 de octubre de 1862): 544-545.

${ }^{14}$ Boletín Eclesiástico de Obispado de Osma 68 (10 de octubre de 1862): 545.
} 
Durante el siglo XIX, tras el primer boletín eclesiástico de Toledo, iniciaron su andadura otros sesenta, siendo el último en publicarse en ese siglo el de Menorca en 1891; a estos se añadieron otros tres en 1950 y el de Huelva en 1954, según Cárcel Ortí. ${ }^{15} \mathrm{Al}$ igual que la fecha de aparición de los boletines, su periodicidad fue también diferente, pues algunos se publicaron semanalmente - un día fijo o variable- y otros quincenal o mensualmente. En la mayoría de los casos, los prelados ordenaron que se encuadernasen en forma de libro al estar paginados correlativamente cada año, y que los volúmenes se conservasen en las parroquias.

Conviene recordar que la división eclesiástica española varió en los siglos XIX y XX. El Concordato de 1851 adaptó la división territorial de las diócesis (artículos $5^{\circ}, 6^{\circ}$ y $7^{\circ}$ ) a la de las provincias civiles que había introducido el régimen liberal, especialmente por el excesivo territorio de algunas (Santiago o Toledo) y para evitar complicaciones administrativas. Se conservaron ocho sillas metropolitanas y se creó, además, la de Valladolid; esta división provocó cambios de adscripción que afectaron a la ubicación de la documentación histórica, permaneciendo en las antiguas sedes episcopales en unos casos y siendo trasladada en otros.

De las nueve iglesias metropolitanas que estableció dicho Concordato, sondeamos trece boletines pertenecientes a cinco de ellas (Burgos, Valencia, Valladolid, Toledo, Santiago y Sevilla); son, por tanto, una muestra que permite conocer la actuación e interpretación de su tarea que cada obispo hacía en su demarcación. Los boletines consultados, disponibles en bibliotecas y hemerotecas digitales o conservados en archivos diocesanos, ${ }^{16}$ son el Boletín Eclesiástico del Obispado de Astorga (1852-1923), Boletín Eclesiástico del Arzobispado de Burgos (1860, 1863, 1871-1872), Boletín Eclesiástico del Obispado de Córdoba (1920, 1927, 1931), Boletín del Clero del Obispado de León (1853-1922), Boletín Oficial

\footnotetext{
15 Vicente Cárcel Ortí, «Los Boletines oficiales eclesiásticos de España», Hispania sacra 37, no. 19 (1966): 48-50.

16 Salvo el Boletín Eclesiástico de Oviedo que fue consultado en el Archivo diocesano de esta ciudad, el resto de ellos, en las fechas indicadas, están disponibles en dos hemerotecas y una biblioteca: Biblioteca Virtual de Prensa Histórica (http://prensahistorica.mcu.es/es/consulta/busqueda.cmd), Galiciana. Biblioteca dixital de Galicia (http://biblioteca.galiciana.gal/es/publicaciones/listar_numeros. cmd) y Biblioteca Digital de Castilla y León (https://bibliotecadigital.jcyl.es/es/estaticos/contenido. cmd?pagina=estaticos/inicio).
} 
Eclesiástico del Obispado de Menorca (1921-1930), Boletín Eclesiástico del Obispado de Mondoñedo (1897-1909; 1911-1913 y 1929), Boletín Eclesiástico del Obispado de Osma (1853-1924), Boletín Oficial Eclesiástico del Obispado de Oviedo (1865-1931), Boletín Eclesiástico del Obispado de Plasencia (1859-1864), Boletín Oficial Eclesiástico del Arzobispado de Santiago (1862-1931), Boletín Oficial Eclesiástico de la Diócesis de Segovia (1867 y 1892-1896), Boletín Eclesiástico del Obispado de Sigüenza (1859-1863 y 1887) y Boletín Eclesiástico del Obispado de Tuy (18591899). ${ }^{17}$ Aunque el origen de este texto está — como ya hemos señaladoen una investigación sobre las relaciones de la iglesia con la enseñanza primaria, los años consultados corresponden a los números accesibles desde la firma del Concordato hasta 1931; no obstante, entre esos años algunos tuvieron números secuestrados ${ }^{18}$ en varias ocasiones, siendo interpretado este hecho por la autoridad eclesiástica como un ataque a la libertad de la Iglesia católica y a la autoridad de los obispos.

Los boletines debían publicar los documentos de la Santa Sede, las disposiciones oficiales del gobierno sobre asuntos eclesiásticos y los escritos del prelado y de otros organismos de la diócesis; además, solían reproducir tanto las pastorales colectivas de los obispos como las de prelados de otras diócesis, convirtiéndose así en «instrumento de mentalización y coordinación de la pastoral diocesana»,19 para lograr una unidad de acción de la Iglesia católica. Todos los boletines recogieron los enfrentamientos de la dicha iglesia con la prensa liberal que cuestionaba a la institución eclesiástica, e intercalaron, para reforzar sus argumentos, artículos tomados de otras revistas y periódicos.

\footnotetext{
${ }_{17}$ Para algunos boletines hay más años reproducidos digitalmente, pero circunscribimos la búsqueda a las fechas de este artículo, es decir, hasta 1931. Algunas de las cabeceras de estas publicaciones fueron ligeramente modificadas en años posteriores, pero son fácilmente identificables por lo que no hacemos constar ese cambio en el nombre. En las notas siguientes nos referiremos a cada publicación de manera abreviada: B.E.O. Astorga; B.E.A. Burgos B.E.O. Córdoba; B.C.O. León; B.O.E.O. Menorca; B.E.O. Mondoñedo; B.E.O. Osma; B.O.E.O. Oviedo; B.E.O. Plasencia; B.O.E.A. Santiago; B.O.E.D. Segovia; B.E.O. Sigüenza y B.E.O. Tuy, respectivamente.

18 Por ejemplo, el Boletín Eclesiástico del Obispado de Osma, que nació el 5 de noviembre de 1853, fue secuestrado por el gobernador civil en 1855, restableciéndose e iniciando su segunda época en diciembre de 1860, siendo nuevamente secuestrados varios meses de 1876, tal y como recoge el número de diciembre de ese año.

19 Leandro Higueruela Pino, «En torno a la bibliografía del Boletín Eclesiástico de la diócesis de Toledo en el siglo XIX», Hispania Sacra. Revista de Historia eclesiástica de España 31, no. 61 (1978): 571.
} 
La información de estos boletines estaba destinada a un público especializado, principalmente al clero secular, por tanto, con textos en latín y en español, resultando su lenguaje a veces inextricable. No obstante, a través de estos sacerdotes las directrices de la Iglesia católica llegaban a la población, pues los prelados recomendaban al final de algunas de sus cartas pastorales y circulares que se leyeran a los fieles, alcanzando sus mensajes a una audiencia mayor que la que cabía esperar dada la escasa tirada, consiguiendo, por esta vía, más difusión que otros periódicos. Como señala $\mathrm{M}^{\mathrm{a}}$ Pilar Salomón, esta «no es una cuestión baladí, por cuanto tenía repercusiones más allá del terreno religioso».20 Esta estrategia permitía una unidad de acción del clero para conseguir y mantener la adhesión de los feligreses y movilizarlos para contrarrestar los ataques a la Iglesia católica.

En cuanto a las cuestiones educativas, en las páginas de estos boletines se recogieron tanto el pensamiento consolidado de la Iglesia católica como sus preocupaciones, intereses y criterios, lo que permite vislumbrar las actuaciones que planeó y aquellas que llevó a cabo desde mediados del siglo XIX, reflejando la defensa que hizo de la enseñanza católica, en un proceso paralelo al crecimiento de la red de escuelas públicas y evidenciando, mayoritariamente, la mutua colaboración entre el poder civil y el religioso. Sin embargo, durante el primer tercio del siglo XX, dicha iglesia empezó a sentirse cuestionada por una parte de la sociedad española y emprendió diversas acciones para conservar su posición.

\section{LOS TEMAS EDUCATIVOS ABORDADOS EN LOS BOLETINES ECLESIÁSTICOS}

En los boletines eclesiásticos aparecen varias cuestiones relacionadas con la educación de la infancia y con la actuación de padres, maestros, inspectores y párrocos en relación con ella. Estructuramos este apartado en dos partes, en función del uso que se puede hacer de esta fuente de información, útil para completar o mejorar el conocimiento de cuestiones ya investigadas, o como punto de partida para nuevos estudios sobre algunas condiciones o situaciones de la enseñanza primaria.

\footnotetext{
20 Salomón Chéliz, «Mucho más que religión», 195.
} 


\section{Los boletines eclesiásticos como fuente complementaria}

A continuación, aludimos a algunas cuestiones que, siendo conocidas, pueden ser reconsideradas al manejar esta fuente especializada cuya información traslada el pensamiento y actuación de la Iglesia católica.

Los conflictos y enfrentamientos entre el poder civil y el religioso surgieron en varios momentos. Un primer caso, dentro del periodo de este estudio, tuvo lugar cuando el episcopado español alertó de las consecuencias de la Revolución de septiembre de 1868 y reclamó y protestó ante las Cortes en 1873 por el proyecto que pretendía separar a la iglesia del estado. Los obispos españoles se apoyaron en las constituciones de 1869 y luego en la de 1876 para defender sus posiciones en relación con la libertad de enseñanza entendida como libertad de creación de centros docentes, y poner en marcha escuelas católicas que hicieran frente a las protestantes, las laicas y al «monopolio del estado docente». Otro caso nos lo proporciona la «cuestión universitaria» provocada durante el mandato de Orovio - como ministro Fomento-, que fue zanjada por la circular de Albareda, del 3 de marzo de 1881, ministro que inauguró una colaboración intensa con el pensamiento pedagógico de la Institución Libre de Enseñanza. La situación tornó de nuevo con el ministerio de Pidal y Mon, que estableció las condiciones que regirían los establecimientos privados de enseñanza por decreto de 18 de agosto de 1885 , rechazando en su preámbulo el monopolio del estado en cuestiones de enseñanza y favoreciendo la creación de centros educativos.

Nuevos casos de enfrentamiento surgieron a comienzos del siglo XX. La jerarquía eclesiástica tuvo muchos quebraderos de cabeza al prever una limitación del papel del clero, a raíz de tres reales decretos aprobados en 1913, que avivaron el miedo de la Iglesia católica a perder prerrogativas en relación con la enseñanza primaria. Uno de ellos reestructuró las Juntas municipales y provinciales de primera enseñanza de las que formaba parte un eclesiástico, otro reorganizó la inspección de enseñanza primaria y el tercero, conocido como Decreto del catecismo, declaró que eran obligatorias las enseñanzas de la Doctrina cristiana y Nociones de Historia Sagrada en las escuelas públicas de instrucción primaria, pero los padres podían rehusar esta enseñanza para sus hijos «por profesar religión distinta de la católica». ${ }^{21}$

${ }^{21}$ Artículo $2^{\circ}$ del Real Decreto relativo a las enseñanzas de la Doctrina cristiana y nociones de Historia Sagrada en las escuelas públicas, Gaceta de Madrid 116 (26 de abril de 1913): 287. Los otros dos 
Este mismo año el arzobispo de Toledo señaló, en una carta circular a los demás prelados, los agravios de las nuevas disposiciones civiles sobre instrucción pública al ser percibidas como contrarias a los derechos de la iglesia:

tales son, por no citar más que algunas, el señalamiento de la peligrosísima coeducación sexual como orientación pedagógica, las reformas de la Escuela Superior del Magisterio con detrimento de la enseñanza de la Religión, la merma de atribuciones en los profesores de la expresada asignatura, las bibliotecas circulantes con libros contenidos en el Índice, la secularización completa de las Escuelas Normales dirigidas por Religiosas, los ataques a la libertad de enseñanza garantizada por la Constitución, la dispensa en favor de los disidentes de asistir a la explicación del Catecismo en las escuelas, la supresión de los exámenes para la asignatura de Religión en los Institutos, la abolición de los privilegios concedidos de antiguo a las Órdenes docentes, la postergación del párroco en las Juntas locales de primera enseñanza, el influjo escandaloso de los sectarios en los altos Centros directivos, y el real decreto de 5 de mayo último, que, a infracciones legales positivas juntaba el no mencionar, en modo alguno, la intervención de la iglesia al disponer detallada y extensamente la inspección de la enseñanza. ${ }^{22}$

Los eclesiásticos vieron reducida su intervención en la enseñanza en cuanto a su participación en las juntas de instrucción pública y a sus derechos de inspección y de enseñanza, al no poder el párroco preguntar el catecismo a los niños — como miembro de la junta municipal de enseñanza- durante la visita a la escuela. Precisamente, la enseñanza del catecismo había sido una preocupación ya sentida en la Iglesia católica por el papa Pio X, quien publicó la carta encíclica Acerbo nimis (1905) sobre la ignorancia religiosa, recordando a los sacerdotes que debían renovar esta enseñanza, que era abordada tanto en la escuela ${ }^{23}$ como en

reales decretos se aprobaron el 5 de mayo de 1913; véase Gaceta de Madrid 133 (13 de mayo de 1913): 446-457.

22 B.E.O. Osma 14 (29 de julio de 1913): 216-217. Esta circular del 18 de junio de 1913 fue reproducida y suscrita por varios obispos; véase B.E.O. Astorga 15 (1 de agosto de 1913); B.O.E.O. Menorca 397 (15 de septiembre de 1913), y otros boletines.

${ }^{23}$ Machaconamente los obispos ordenaban publicar cómo debían abordar los párrocos y maestros esta enseñanza, apelando a la legislación vigente según ellos y haciendo partir toda ella del 
las parroquias, existiendo en varias diócesis organizaciones para ello, como la Santa Obra del Catecismo en Oviedo, la Junta Central de Enseñanza del Catecismo en Osma, ${ }^{24}$ etc., con la finalidad de preparar a los niños para la primera comunión; sin embargo, la Iglesia católica consideró que no se estaba enseñando bien la doctrina cristiana, y de ahí la citada encíclica que dio paso a una reorganización de estas enseñanzas tanto para niños como para adultos.

En esta línea, el Vaticano tuvo la intención de elaborar un texto único del catecismo para todo el orbe católico en 1917 y pidió a todos los obispos que enviaran tres ejemplares de los utilizados en sus diócesis, ${ }^{25}$ si bien tomó la decisión de hacer un texto diferente por naciones o lenguas, no llegó a publicarse en España durante el periodo que abarca este estudio. La preocupación por cómo enseñar el catecismo también estuvo presente en los Congresos catequísticos nacionales celebrados en Valladolid (1913), Granada (1926) y Zaragoza (1930), dando cuenta los boletines eclesiásticos de las inquietudes y medidas tomadas para la renovación metodológica.

Como fuente, los boletines informan, lógicamente, de otras iniciativas de la Iglesia católica para extender sus enseñanzas, pues la jerarquía eclesiástica puso en marcha acciones colectivas abordando cuestiones educativas propias de la enseñanza católica, que afectaron a la educación en general. Tal es el caso de los congresos católicos (Madrid 1889, Zaragoza 1890, Sevilla 1892, Tarragona 1894, Burgos 1899 y Santiago

Reglamento de las escuelas públicas de instrucción primaria elemental del 26 de noviembre de 1838, habiendo, sin embargo, normativa posterior - Concordato de 1851 y Ley Moyano de 1857-. Son muchos los ejemplos de este recordatorio en los boletines eclesiásticos durante el periodo de este estudio.

${ }^{24}$ En Oviedo había comenzado en 1869 y sobre su enseñanza pueden verse, por ejemplo: «Funciones de los catecismos de los niños y niñas de esta capital», B.O.E.O. Oviedo 5 (12 de febrero de 1873): 70-73; las instrucciones sobre la enseñanza del catecismo en 4 (15 de febrero de 1885):49-67, y la Circular $\mathrm{n}^{\circ} 22$ (15 de noviembre de 1885): 477-479, en la que se denunciaban las ediciones erróneas del catecismo del Padre Astete que se usaban en la diócesis y se ordenaba utilizar desde entonces el Catecismo de la Doctrina Cristiana para la Diócesis de Oviedo. En esta diócesis se publicó una revista mensual, La santa obra del catecismo, y sobre estas enseñanzas se centra la carta pastoral y el decreto publicado en el 5 (1 de marzo de 1924):65-97. En el caso de Osma véase, por ejemplo, la Circular $\mathrm{n}^{\circ} 39$ en B.E.O. Osma 2 (30 de enero de 1899), y la Circular n 199 nombrando una Junta Central Diocesana de enseñanza del catecismo y disponiendo que en las parroquias se constituyesen juntas locales, en 18 (30 de septiembre de 1905):275-277 y otros.

${ }_{25}$ Véase, por ejemplo, «Sobre el texto único del catecismo», B.O.E.O. Oviedo 22 (15 de noviembre de 1918): 349-350. 
1902), que incorporaron una sección sobre educación. En 1902, con ocasión del de Santiago de Compostela, los obispos enviaron un mensaje a Alfonso XIII para recordarle los derechos de la iglesia, entendiendo que habían sido olvidados «en recientes disposiciones sobre Instrucción Pública no oficial». ${ }^{26}$ Actos similares fueron las asambleas de enseñanza, las reuniones de las asociaciones de maestros católicos y las de las asambleas nacionales de la prensa católica, donde se abordaron cuestiones educativas. Específicamente sobre enseñanza trató el I Congreso Nacional de la Educación Católica celebrado en Madrid en 1924. Sobre todos estos eventos se expresaron los obispos individual y colectivamente, quedando estas acciones y opiniones recogidas en las páginas de estos boletines.

Finalmente, además de lo expresado, los boletines también dan cuenta de la actividad desarrollada en los centros educativos vinculados a la Iglesia católica, tales como los seminarios conciliares o diocesanos, los seminarios menores como el de Val-de-Dios en Asturias ${ }^{27}$ o el de Sigüenza, asimilados a los institutos oficiales de segunda enseñanza en 1885, las escuelas dominicales o los colegios de diversas congregaciones, que habían proliferado durante el último cuarto del siglo XIX y en los primeros años del siglo XX. ${ }^{28}$

\section{Propuestas de investigación}

Además de los asuntos señalados, como propuestas de investigación a partir del contenido de los boletines eclesiásticos, presentamos someramente otros aspectos educativos para los que es útil su consulta, pues son tratados en sus páginas y requerirían ser abordados en mayor profundidad: las quejas por la existencia de escuelas no católicas y las

\footnotetext{
${ }^{26}$ B.O.E.A. Santiago 1661 (11 de agosto de 1902):371, texto reproducido en el boletín de otras diócesis.

27 Véase B.O.E.O. Oviedo 24 (1 de diciembre de 1885):497-498. Desde entonces se incorporan noticias sobre la actividad académica de este centro, del número de alumnos matriculados y premiados, de los exámenes, etc.

${ }_{28}$ Algunos provenían de Francia como los Hermanos de las Escuelas Cristianas que llegaron a España en 1878, los Salesianos en 1881, la Compañía de María en 1887, etc. Otros eran de origen español como las Dominicas de la Anunciata —congregación fundada en 1856 en Vich para dedicarse a enseñar a niñas pobres- de cuya instalación en la diócesis de Oviedo da noticia su boletín en 1891; el B.O.E.O. Oviedo 22 (15 de noviembre de 1900): 349, también reprodujo la Real Orden disponiendo el reconocimiento de la existencia legal en España del Instituto religioso de Hermanas Terceras Dominicas de la Anunciata en 1900.
} 
razones aducidas, la defensa de la infancia en países con otras religiones, la denuncia del comportamiento de algunos profesionales de la enseñanza, el fomento del asociacionismo de los maestros católicos o la vigilancia sobre los libros utilizados en las escuelas; asuntos que abordamos a continuación.

\section{Rechazo de las escuelas no católicas}

Los prelados vieron con preocupación la existencia de escuelas no católicas en sus demarcaciones manifestando un rechazo expreso a las vinculadas a otras religiones o ideologías, como las protestantes, las árabes de observancia musulmana, las neutras... La actitud del clero y de los católicos hacia la existencia de este tipo de enseñanzas fue siempre de rechazo, pero la defensa que hizo de la enseñanza católica fue diferente en cada coyuntura. En este sentido, detectamos que a mediados del siglo XIX las preocupaciones de los obispos al respecto se focalizaban en las escuelas protestantes que estaban instaladas en sus diócesis; por ejemplo, tanto el obispo de Oviedo como el arzobispo de Santiago de Compostela anunciaron cada conversión al catolicismo de algún miembro de esas confesiones, alertando y llamando la

atención de los padres de familia y de todos nuestros diocesanos sobre la gravedad del pecado que comenten los que contribuyen al sostenimiento de escuelas protestantes, cuyo pecado ha sido incluido en las Constituciones Sinodales en la lista de los reservados a nuestra autoridad. ${ }^{29}$

A lo que añadían que también pecan «los que arriendan o alquilan sus casas para escuelas protestantes o laicas». La preocupación de los católicos parece excesiva si tenemos en cuenta que, según la estadística escolar de España realizada por la Subsecretaría del Ministerio de Instrucción Pública y Bellas Artes, mandada publicar en 1908 en los boletines oficiales, había en el país un total de 91 escuelas protestantes y 107 laicas frente a las 5.014 católicas.

\footnotetext{
29 Véase la «Carta Pastoral sobre "El amor a la santa madre iglesia"», B.O.A. Santiago 1.828 (9 de febrero de 1907): 59. En años previos, el boletín de esta diócesis recogía también estas ideas como en el $n^{\circ} 1.287$ (30 de mayo de 1892): 237.
} 
Precisamente, la proliferación de escuelas privadas laicas y neutras al final de la primera década del siglo XX, provocó que la jerarquía eclesiástica presentara varias quejas al gobierno. Entre 1909-1910 abundaron los rumores de una posible apertura de las clausuradas por el gobierno de Maura y los obispos argumentaron para impedirlo que eran «escuelas ilegales» y «de carácter antirreligioso e inmoral». ${ }^{30}$ Los católicos se pusieron en guardia contra las ideas de los librepensadores, los socialistas, los anarquistas, los ateos y los positivistas cuya extensión les resultaba alarmante, calando en la sociedad y subvirtiendo el orden social, animando la jerarquía eclesiástica a los feligreses a manifestarse públicamente. ${ }^{31}$ Arzobispos y obispos recuerdan

la obligación que tienen los padres de familia de prohibir a sus hijos la concurrencia a las escuelas laicas o neutras, de las cuales se halla excluida la instrucción religiosa; y [...], recordamos a los curas párrocos la obligación de visitar las escuelas de su demarcación respectiva según dispone la constitución sinodal 265.32

Les preocupaba la extensión del laicismo, no sólo el más antirreligioso que para ellos representaba la Escuela Moderna de Ferrer Guardia, sino también las escuelas vinculadas a la Institución Libre de Enseñanza y, para defenderse, apelaban a la legislación vigente, argumentando ante el Presidente del Consejo de Ministros, que

su existencia es opuesta a la ley internacional que se llama concordato, en cuyo artículo $2^{\circ}$ se promete que la «instrucción en las escuelas públicas o privadas de cualquier clase será en todo conforme a la doctrina de la misma Religión Católica»; y a la ley de Instrucción Pública, cuyos artículos 295 y 296, mandan cumplir, dando normas para ello, lo acordado entre las dos potestades; y a la ley fundamental o Constitución de la Monarquía, en cuyo

\footnotetext{
${ }^{30}$ Ejemplos son la «Carta Pastoral de los prelados reunidos», B.O.O. Tuy (16 de octubre de 1906); la «Exposición contra la existencia de las escuelas llamadas laicas» o la «Exposición hecha al presidente del Consejo de Ministros para felicitarlo por haber reprimido los "gravísimos desordenes ocurridos en Barcelona"», B.O.E.A. Santiago (10 de diciembre de 1909) y (9 de octubre de 1909); y la «Carta Pastoral sobre los deberes de los católicos en las actuales circunstancias», B.O.A. Santiago 2.005 (11 de diciembre de 1911): 571-578, todas reproducidas en otros boletines.

31 Véase en el B.O.E.O. Menorca 416 (10 de julio de 1914), la manifestación para que no se abriera la escuela laica de Alamayor.
}

32 B.O.A. Santiago 2.005 (11 de diciembre de 1911): 578. 
artículo 11 no se permite otras «manifestaciones públicas que las de la Religión del Estado» y manifestación pública es la del profesor que en una escuela pública delante de sus alumnos combate todos los fundamentos del orden religioso. ${ }^{33}$

Simultáneamente, se animaba a los párrocos desde los boletines para que se inscribieran como participantes en la Asamblea de Enseñanza y Educación que había convocado el Ministerio de Instrucción Pública en Madrid, en 1910, para «conocer, en el sentido de la doctrina y en el de los métodos y procedimientos técnicos, todos los estados de opinión». ${ }^{34}$ Los católicos estaban convencidos de que la mayoría de los asambleístas abogarían por la enseñanza neutra, detectando «una determinada tendencia hacia la que pudiera llamarse pedagogía racionalista, laica y liberal»,35 lo cual iba en contra de los intereses de la Iglesia católica. Los prelados pidieron a los párrocos que animaran a sus feligreses a participar, recordándoles quiénes podían ser miembros de la citada Asamblea: cualquier vocal de las juntas de instrucción primaria, los maestros de los colegios particulares, todos los que tuvieran un grado universitario estatal, los autores de tratados pedagógicos y los periodistas. ${ }^{36}$ Esta Asamblea se retrasó y no llegó a celebrarse como se tenía previsto al inscribirse 5.700 personas (de los cuales 4.000 eran católicos), ${ }^{37}$ cantidad imposible de reunir en un local, lo que provocó que la intervención y el voto individuales se convirtieran en participación corporativa. Los obispos siguieron animando a participar a todos los maestros católicos, informando desde estos boletines de las actividades de la Asociación Benéfica de la Enseñanza Católica establecida en Madrid, que quería las

\footnotetext{
33 «Exposición que los Rvmos. Prelados de España han dirigido al Excelentísimo Sr. Presidente del Consejo de Ministros, contra la existencia de las escuelas llamadas laicas», B.O.O. Osma 26 (30 de noviembre de 1909): 335-341, y B.O.E.O. Oviedo 23 (1 de diciembre de 1909): 348-349.

${ }_{34}$ La Asamblea había sido convocada por Real Decreto de 18 de septiembre de 1910. Gaceta de Madrid 265 (22 de septiembre de 1910): 830, y el cuestionario con los asuntos a tratar se publicó por Real Orden de 19 de octubre de 1910, Gaceta de Madrid 293 (20 de octubre de 1910): 198.

35 B.E.O. Mondoñedo 24 (30 de agosto de 1911): 379.

36 B.O.E.O. Oviedo 26 (15 de diciembre de 1910): 387-388.

37 Véase la exposición del Real Decreto de 17 de marzo de 1911, Gaceta de Madrid 77 (16 de marzo de 1911): 767. De nuevo fue prorrogada por Real Orden de 26 de mayo de 1911, Gaceta de Madrid 150 (30 de mayo de 1911): 590. Estas cifras nos las proporciona Teódulo García Regidor, «La actitud de la Iglesia española ante la política educativa del Estado y el fenómeno de la secularización docente. La segunda mitad del siglo XIX y siglo XX» en Historia de la acción educadora de la iglesia en España, dir. Bartolomé Martínez (Madrid: Biblioteca de Autores Cristianos, 1997), t. II, 155.
} 
señas de todos los maestros católicos de España, tanto públicos como privados, para enviarles una circular y folleto referentes a lo que dicha asociación piensa hacer respecto de la Asamblea de Enseñanza, y puedan, si están conformes, enviar su adhesión. ${ }^{38}$

Esta llamada surtió efecto y la Asociación Benéfica de la Enseñanza Católica tomó varios acuerdos en relación con las preguntas del cuestionario de la Asamblea de Enseñanza. Por unanimidad pidió que el estado prohibiera toda escuela no católica; que el gobierno apoyara a los obispos para impedir la circulación y uso en la enseñanza de malos libros; que el «Estado debe conceder libertad académica a la Iglesia sin sujeción a centros oficiales docentes, como lo ofrece el art. 12 de la Constitución», y que la instrucción en cualquier centro público o privado «debe ser en todo conforme a la Religión Católica, que es la religión del Estado, y éste debe autorizar y dar medios a los Obispos para que puedan velar eficazmente sobre el cumplimiento de esta prescripción concordada». ${ }^{39}$ Como sintetiza García Regidor, los católicos quisieron mostrar su poder al "prejuzgar, que esta convocatoria, aunque abierta a todos, es una cuestión de fuerzas - las izquierdas laicas contra las derechas católicas— $\gg .40$

De los enfrentamientos ideológicos y de las estrategias utilizadas por los laicistas da cuenta el Boletín de la diócesis de Oviedo a la vez que reconoce que la

brillantísima y persistente campaña de los católicos españoles contra las escuelas laicas ha logrado sacar de quicio y enloquecer hasta el delirio a los impíos y revolucionarios, los cuales en vez de la lucha noble y digna que es el terreno donde desenvuelven su acción los católicos apelan ya a medios tan miserables e indecorosos como

\footnotetext{
38 B.O.O. León 16 (31 de agosto del 1911): 455. Este anuncio se insertó en otros como el B.O.O. Osma 17 (11 de septiembre de 1911): 272. En el de Mondoñedo 24 (30 de agosto de 1911): 378-381, se informa del desarrollo de la Asamblea y se reproduce la circular enviada por la Asociación Benéfica de la Enseñanza Católica, tomándola del de Jaén.

39 B.O.O. Osma 19 (14 de octubre de 1911): 294. Estos acuerdos y reivindicaciones se publicaron en otros boletines como el de Astorga 16 (22 de agosto 1911) o el de León 21 (15 noviembre de 1911) con el texto «Me adhiero y las adopto sin reserva. (sello de la Escuela). (firma). (Títulos y categoría del firmante)».

40 Teódulo García Regidor, «La actitud de la Iglesia española ante la política educativa del Estado y el fenómeno de la secularización docente», 154.
} 
es, entre otros, la publicación y reparto de unas supuestas Hojitas piadosas con el título de “¡Abajo las escuelas laicas!», donde bajo esa supuesta apariencia se vierten las más estupendas mentiras y calumnias contra las escuelas religiosas y especialmente contra las dirigidas por las Congregaciones religiosas. ${ }^{41}$

Sospechando que dichas hojas estaban presentes en la diócesis, el obispo previno a los párrocos, maestros y padres para que "procuren recoger e inutilizar dichos impresos y cualesquiera otros análogos en que se trate de engañar y pervertir a los incautos». ${ }^{42}$

Otra cuestión polémica fue la autorización que Alfonso XIII dio el 1 de julio de 1921 a una estudiante de magisterio de religión israelita dispensándola de los dos cursos de religión católica, provocando las quejas la Congregación Mariana del Magisterio y del Arzobispo de Toledo que solicitaron la derogación de esta real orden, consiguiendo que se aclarara

en el sentido de que la dispensa del examen de Religión a los alumnos y alumnas musulmanes o israelitas que cursen sus estudios en las Escuelas Normales les impide ejercer las funciones del Magisterio nacional en los territorios situados fuera de África; y aun en las plazas fuertes españolas y territorios comprendidos en la zona del protectorado solo podrán ejercer su misión docente respecto a sus mismos correligionarios, quedando la enseñanza de las Escuelas del Estados enclavadas en ellos encomendada exclusivamente a los Maestros nacionales. ${ }^{43}$

Los hechos aludidos muestran cómo las páginas de estos boletines nos trasladan la actitud defensiva y empecinada de la jerarquía eclesiástica y de algunos católicos frente a otras opciones religiosas o ideológicas, yendo más allá de la autodefensa al negar la posibilidad a opciones educativas minoritarias alejadas de lo católico, llegando incluso a solicitar la participación de los niños españoles en la cristianización de los de otros países. En relación con lo anterior, fue el cardenal arzobispo de Toledo, Juan José Bonel y Orbe, el que propuso, en 1852, la introducción

\footnotetext{
41 «Sección de noticias. Alerta», B.O.E.O. Oviedo 9 (2 de mayo de 1910): 155.

${ }^{42}$ B.O.E.O. Oviedo 9 (2 de mayo de 1910): 155.

${ }_{43}$ Real Orden de1 de septiembre de 1921 reproducida en B.O.E.O. Menorca 561 (12 de octubre de 1921): 193-194 y en B.O.E.D.O. Oviedo 20 (1 de octubre de 1921): 84-85.
} 
en España de la obra de la Santa Infancia y así lo recogieron los boletines eclesiásticos desde 1853.44 Esta institución pionera en la defensa de la infancia - pues se adelantó a la Declaración de Ginebra de 1924 sobre los derechos del Niño- había nacido en 1843 en Francia, por iniciativa del obispo de Nancy y de Toul, Carlos Augusto de Forbin-Janson, teniendo por finalidad rescatar, bautizar y educar inicialmente a los niños chinos y, al poco tiempo, a los de otros países que permitían y toleraban impunemente el infanticidio y el filicidio. La finalidad de esta organización era que los niños cristianos se asociaran a ella hasta que hicieran la primera comunión, que rezaran diariamente y dieran una cierta cantidad de dinero para que otros niños de tierras lejanas tuvieran la posibilidad de sobrevivir, de salir de la miseria y ser bautizados y educados cristianamente, pues los misioneros «se ocupan de comprar los niños vendidos por sus desnaturalizados padres en dos, tres o cuatro pesetas cada uno, y aun en dos reales».45 Con lo recaudado y la labor de los misioneros se construían orfanatos y escuelas regentados por varias congregaciones (agustinos, dominicas, franciscanos, jesuitas, hermanas de la caridad...).

El reglamento dado por el obispo de Nancy y Toul en 1843 y los estatutos fueron reproducidos en estos boletines, ${ }^{46}$ así como su historia, una vez que llegó a España en 1852 bajo el patrocinio de la reina Isabel II, quien admitió su establecimiento por Real Despacho de 21 de diciembre de ese año. Quiso que su hija, la Princesa de Asturias, ostentase los títulos de primera asociada, fundadora y protectora de esta obra, y ordenó publicar la documentación correspondiente y otros detalles, además de la constitución de la obra en España, pues eran precisas algunas modificaciones para adaptarla a nuestro país, determinando, por ejemplo, que

\footnotetext{
44 B.E.O. Osma 22 (29 de enero de 1853): 131, y en el número 61 (10 de diciembre de 1853): 6-7 informa de su constitución en Sevilla el 7 de noviembre de 1853; B.C.O. León 9 (26 de febrero de 1853): 65-69, y la circular estableciendo esta obra en B.C.O. León 60 (18 de febrero 1854): 473-477. Poco a poco se fue poniendo en marcha en otras diócesis, así en la de Astorga se inició en 1865, véase B.E.O. Astorga 565 (1 de junio de 1865): 160-168. En este mismo boletín se habla periódicamente de ella, por ejemplo 24 (15 de diciembre de 1923): 374-376. En todos los boletines, se da regularmente cuenta de las reuniones, lo recaudado, etc.

45 B.E.O. Osma 20 (18 de marzo de 1854): 154.

46 B.E.O. Osma 21 (24 de marzo de 1854):163-167, y 22 (1 de abril de 1854): 174-176.
} 
lo recaudado fuera enviado, a través de la central establecida en París, a las misiones atendidas por españoles. ${ }^{47}$

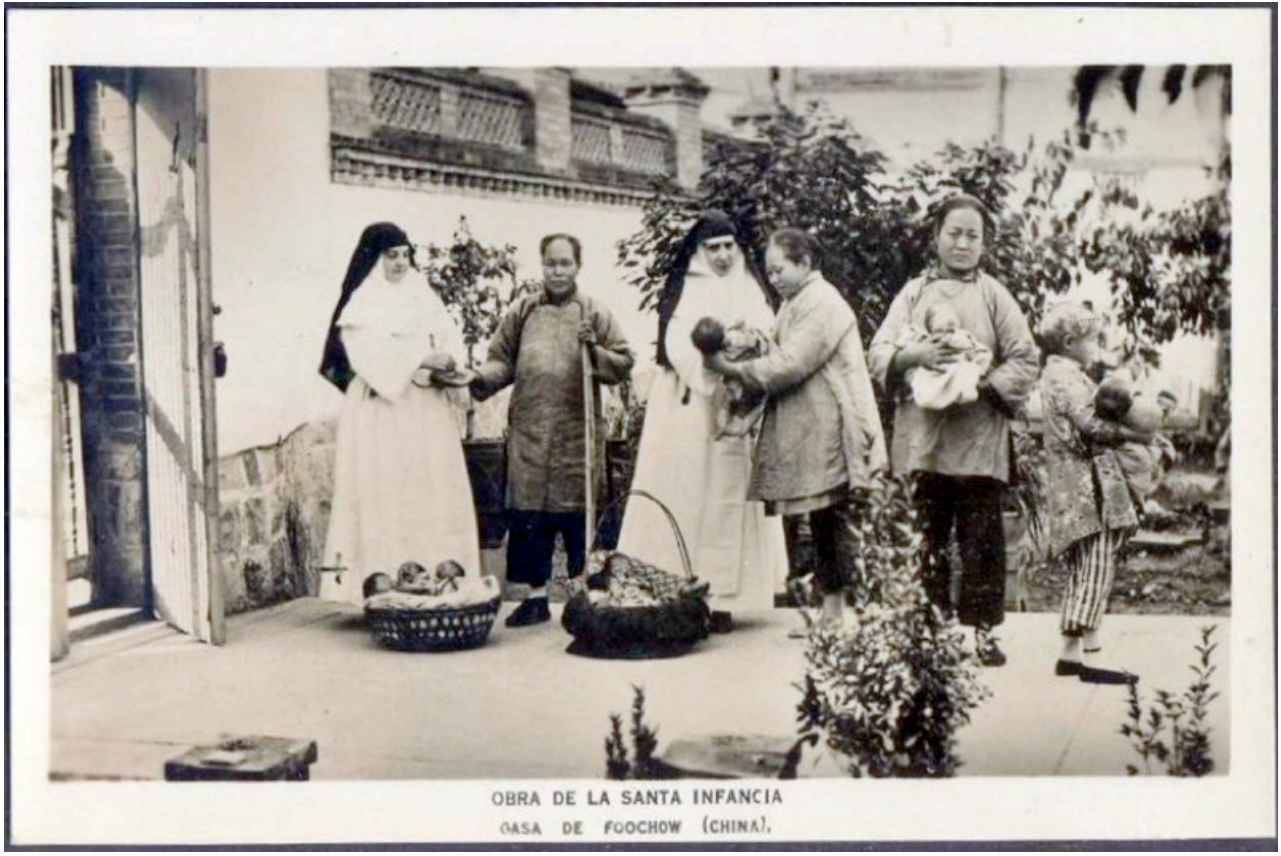

Imagen 1. Tarjeta postal «Obra de la Santa Infancia». Editorial Talleres Fotográficos Guilera, Barcelona (c. 1920). ${ }^{48}$

Esta organización fue transformándose y consiguiendo el apoyo de varios papas como Gregorio XVI (17 de marzo y 2 de mayo de 1846) y Pío IX (10 de enero de 1847 y 12 de febrero de 1851), quienes concedieron indulgencias a los asociados y cooperadores; 49 Pío XI le dio el carácter de obra Pontificia el 3 de mayo de 1922 y Pío XII instituyó el día mundial de la Santa Infancia el 4 de diciembre de 1950. En España fue la Dirección General de Enseñanza Primaria la que en enero de 1953

\footnotetext{
47 Véase B.E.O. Osma 23 (1 de abril de 1854): 181-182.

48 Archivo China-España (1800-1950), disponible en http://ace.uoc.edu/exhibits/show/misiones-china/item/479. La fotografía original es de Charles Chusseau-Flaviens e ilustra el momento en que misioneras dominicas reciben niñas a cambio de una compensación económica en la Santa Infancia de Fuzhou.
}

49 Véase B.E.O. Osma 22 (1 de abril de 1854): 175-176. 
ordenó a maestros e inspectores celebrar esta fiesta, ${ }^{50}$ que acabó siendo una conmemoración anual habitual en las escuelas. ${ }^{51}$

\section{El control del personal de primera enseñanza}

El papel supervisor de la iglesia sobre la educación primaria en lo que se refiere a los libros, los contenidos y los maestros es conocido; sin embargo, en las páginas de estos boletines se suele aludir a las prácticas religiosas que maestros y escolares debían llevar a cabo los días de precepto y a las iniciativas de los inspectores de primera enseñanza promoviendo estas actividades circum-escolares. La consulta de estos boletines nos ha proporcionado los casos de maestros e inspectores de primera enseñanza denunciados y expedientados por no acompañar a los escolares a los diversos actos religiosos (misa dominical, confesión anual, procesiones...) y, aunque fueron pocos los casos sancionados, la información sobre los mismos apareció de forma reiterada.

Si bien el marco legal en el que se desenvolvió la instrucción pública en España ha quedado señalado en las líneas previas, hay que mencionar nuevamente que desde la segunda mitad del siglo XIX, y hasta mediados los años veinte del siglo XX, la Iglesia católica, algunas juntas locales y provinciales y algunos rectores e inspectores invocaron repetidamente el ya citado Reglamento de 1838, aludiendo especialmente al capítulo V relativo a la instrucción religiosa y moral (artículos 36-49), reactivándolo en algunos casos para controlar el comportamiento del magisterio primario en cuanto a estas enseñanzas y a la asistencia obligada los días festivos a los actos de culto en compañía de los escolares.

Cuando algún maestro no acudía con los niños a los aludidos actos religiosos era reconvenido; si no lo hacía regularmente, los párrocos, como miembros de las juntas locales, o estas directamente, le denunciaban y comenzaba la instrucción del expediente correspondiente. En las páginas de los boletines eclesiásticos se ha dado cobertura y publicidad

\footnotetext{
50 Véase Dirección General de Enseñanza Primaria, «Dictando normas referentes a la celebración de la fiesta de la Santa Infancia», Boletín Oficial del Estado (22 de enero de 1953): 452.

51 Véase, por ejemplo, la parte dedicada a conmemoraciones en los tres grados de la conocida Enciclopedia Álvarez que inició su publicación en 1954 en la editorial Miñón, y se reeditó más de un centenar de veces.
} 
a varias denuncias de maestros de la enseñanza pública que fueron resueltas de dos modos, aplicando o no el citado Reglamento. En seis casos el maestro fue obligado a cumplir las prácticas religiosas con los escolares: los de Cabeza de Béjar (Salamanca, 1875), San Quintín de Mediona (Barcelona, 1891), Vallelado (Segovia, 1893), Duruelo (Soria, 1896), Peñafiel (Valladolid, 1897) y Turre (Almería, 1900). Estos fueron los casos más llamativos y, como la sentencia obligaba al maestro a reconducir su conducta, la Iglesia católica aludió insistentemente a ellos reproduciendo las denuncias y expedientes incluso años después, con la clara intención de animar a los párrocos a continuar controlando el comportamiento de los maestros. Sin embargo, hubo otros casos que, con denuncias similares, no fueron sancionados pues no se les aplicó el Reglamento de 1838, circunstancia facilitada por los vaivenes políticos. En esta situación estuvieron tres maestros de la enseñanza pública: el de Castrillo de Matajudíos (Burgos, 1884-1885), el de Allo (Navarra, 18861890) y el de Albelda (Huesca, 1912). Estas denuncias y expedientes son objeto de un estudio monográfico actualmente en curso.

La jerarquía eclesiástica también se hizo eco en sus boletines de otras destituciones del personal de enseñanza, quizá como advertencia a otros docentes. Así, en 1925 se resolvió el caso de la profesora numeraria de la Escuela Normal de Maestros de Lérida, Josefa Uriz y Pi (18831958) que se había iniciado en 1922 cuando sus clases de Historia de la Pedagogía y los libros que recomendaba fueron puestos bajo sospecha por la directora de dicha Escuela y el rectorado de Barcelona le abrió un expediente administrativo. El conflicto estaba servido, pues muchos profesores (1.272 compañeros, catedráticos e inspectores de primera enseñanza) le manifestaron su apoyo apelando a la libertad de cátedra, pero también las autoridades religiosas intervinieron cuestionando dicha libertad al estar limitada, argumentaban, no solo por la dignidad personal, sino también por la integridad de la vida moral y religiosa de sus alumnos. ${ }^{52}$ Tras proporcionar argumentos al legislador pidieron, el 7 de marzo de 1922, que estos se unieran al oficio de los que defendían la actuación de Josefa Uriz. Como los profesores eran nombrados y

\footnotetext{
52 Véase sobre este asunto las páginas 237-242 de Juan Postius y Sala, La iglesia y la catequesis. Síntesis canónico-legal sobre la enseñanza religiosa en España (Madrid-Barcelona: Corazón de María, 1929). El caso de esta profesora es abordado con detalle en Manuel Martorell Pérez, Salomó Marquès Sureda y $\mathrm{M}^{\mathrm{a}}$ Carmen Agulló Díaz, Pioneras: historia y compromiso de las hermanas Úriz Pi (Tafalla: Txalaparta, 2018).
} 
pagados por el estado, éste tuvo que compaginar la libertad de conciencia, que reconocía el artículo 11 de la Constitución de 1876, con la confesionalidad del Estado. La Real Orden del 27 de febrero de 1925 separó del servicio por un año a la citada profesora. ${ }^{53}$

Otro caso fue el del Inspector Jefe de Primera Enseñanza de Granada Fernando Sainz Ruiz (1891-1959), dado de baja en el escalafón en 1927, por insubordinación, al haberse negado a cumplir la orden ministerial que le pedía que saliera a la calle con los niños de las escuelas públicas para celebrar la entrada del arzobispo en la ciudad. La Real Orden de 15 de diciembre sancionándolo dice que, además de insubordinación y hostilidad al gobierno, manifestó «notoria irreligiosidad» en el desempeño de su cargo y que por eso fue «pernicioso ejemplo para Maestros y educandos». .54

En definitiva, las prácticas y actividades religiosas escolares y extraescolares exigidas a maestros e inspectores de primera enseñanza son una muestra del interés de la Iglesia católica en mantener la intensidad de su presencia en la escuela primaria, dado que en los colegios religiosos estaba garantizada. ${ }^{55}$

\section{Reacción frente a las agrupaciones del magisterio}

El agrupamiento del magisterio para la defensa de sus intereses profesionales y de la religión y moral católica es otra cuestión que se puede seguir en estos boletines que recogían, además, el llamamiento que al mismo hacían otros periódicos católicos.

Durante el último tercio del siglo XIX se habían producido los primeros conatos de organización societaria del magisterio y en ese periodo se crearon y desaparecieron numerosas asociaciones locales y provinciales;

\footnotetext{
53 Véase la Real Orden reproducida en B.O.E.O. Oviedo 19 (septiembre de 1925): 355.

54 B.O.E.O. Oviedo 4 (15 de febrero de 1928): 67.

55 Al respecto, véase Paulí Dávila Balsera, Luis M. Naya Garmendía e Hilario Murua Cartón, «Prácticas y actividades religiosas en los colegios privados del País Vasco durante el siglo XX», Historia y Memoria de la Educación 4 (2016): 151, donde afirman que «las prácticas y actividades religiosas en las escuelas no son más que un correlato que continúa la capacidad de penetración de la religión en el ámbito escolar [...]. Este fenómeno [...] estaba presente en otros centros religiosos e, incluso, en la mayoría de escuelas públicas, sobre todo en el periodo comprendido entre 1939 a 1970»
} 
finalmente, en 1901, había iniciado su andadura la Asociación Nacional del Magisterio, con una estructura federada a la que fueron incorporándose las asociaciones provinciales. Diez años después esta Asociación «cifraba su afiliación en 15.000 maestros, algo más de la mitad de los maestros públicos existentes». ${ }^{56}$ Sin embargo, las discrepancias entre los asociados provocaron la separación de algunos que formaron otras agrupaciones, como la Asociación General de Maestros de orientación socialista, fundada en septiembre de 1912. Un poco antes, en mayo de 1909, los maestros de las escuelas laicas socialistas madrileñas habían creado la Asociación de Maestros Racionalistas, ${ }^{57}$ preocupando a un sector de los católicos la deriva racionalista y de neutralidad religiosa que reclamaban para las escuelas públicas y privadas. Como medio para contrarrestar esta influencia, la Asociación Benéfica de la Enseñanza Católica había establecido, en 1911, la Asociación Católica de Maestros, iniciando al año siguiente una campaña desde el periódico La enseñanza católica, dirigido por Manuel Prieto, que presidía ambas asociaciones, para convertirla en Federación. Varios boletines eclesiásticos reprodujeron el llamamiento y apelaron a los párrocos para que los maestros se agrupasen y participasen en esta Federación Católica de los Maestros Españoles, cuya intención era que nada en la práctica de los afiliados fuera contrario a la religión y moral católicas o al Reglamento de la misma, y quiso «oponerse a que prospere la establecida por cuatro sectarios en la Casa del Pueblo de Madrid»,58 comenzando una campaña para captar a los maestros que trabajaban en la enseñanza pública y en la privada.

La agrupación del magisterio católico partió simultáneamente de religiosos regulares y seculares (Ramón Ruiz Amado, Pedro Poveda, Andrés Manjón...), así como de seglares (Rufino Blanco o Manuel Prieto, entre otros, que dirigían periódicos católicos), si bien se produjeron

\footnotetext{
56 Dato tomado de Aida Terrón Bañuelos, «Cien años de defensa colectiva: la dinámica societaria y sindical del Magisterio Español», Sarmiento. Anuario Galego de Historia da Educación 3 (1999): 164.

57 Esta agrupación contó en 1910 con 42 socios en Madrid, «probablemente su cifra más alta» como afirma Francisco de Luis Martín, Historia de la FETE (1909-1936) (s.l.: FETE, Servicios y Consulting, 1997): 91.

58 Véase «Federación Católica de Maestros Españoles» B.E.O. Mondoñedo 32 (20 de noviembre de 1912): 504, y el mismo texto en B.O.E.O. Oviedo 26 (2 de diciembre de 1912): 373-376, y en B.E.O. Astorga 2 (18 de enero de 1913): 21-25. Sobre esta cuestión también «A los Maestros Españoles. Proyecto de Federación Católica de Maestros Españoles», B.E.O. Mondoñedo 26 (20 de septiembre de 1913).
} 
discrepancias entre ellos y en la forma de articular esa Federación, siendo Poveda su gran impulsor, aunque su nombre se omitiera, tal y como él deseaba. ${ }^{59}$

En estos boletines también se difundieron actividades variadas de las diversas agrupaciones del magisterio, como el XX Certamen científico literario convocado por la Real Asociación de Maestros de Primera Enseñanza San Casiano dando cuenta de los temas y premios. ${ }^{60}$

El estudio de este asociacionismo profesional católico — ya abordado para agrupaciones con otras ideologías-, es aún una tarea pendiente que es posible realizar entretejiendo la información disponible con, por ejemplo, los sugerentes testimonios de maestros católicos que militaron en otras asociaciones. ${ }^{61}$ En definitiva, estos boletines contribuyeron, al igual que la prensa profesional y pedagógica de esos años, a conformar la identidad del magisterio.

\section{Supervisión y denuncia de libros de uso escolar}

Los boletines también dieron cuenta de las novedades bibliográficas, señalaron la autorización o denegación para su lectura, y publicaron y recomendaron las obras de algunos autores católicos. Un ejemplo es la Guía del niño cristiano declarada de texto por Real Orden ${ }^{62}$ y otro son tres obras de María Orberá y Carrión (1929-¿?), que entonces era la

\footnotetext{
$59 \mathrm{Al}$ respecto, es interesante la correspondencia entre Pedro Poveda y los citados, así como con otros católicos. Véase en Flavia Paz Velázquez, Proyectos pedagógicos (Madrid: Narcea, 1987), por ejemplo, la carta de Ruiz Amado, el 23 de octubre de 1912, a Poveda dando cuenta de haber recibido la información: «con gusto trabajaré en ello, como representante que soy de la Federación Internacional. Pero necesito saber quién es esa "Asociación de la Enseñanza Católica" que invita, pues ni ella ni su órgano La Enseñanza Católica me son conocidas» (p. 91), y Pedro Poveda, Epistolario 1898-1917 (Madrid: Narcea, 2012).

${ }^{60}$ B.O.E.O. Oviedo 16 (1 de septiembre de 1920): 251-253.

${ }^{61}$ Un ejemplo es la autobiografía recuperada por Leonardo Borque y Jesús Suárez López (eds.). Julián Campo Zurita (1891-1978). Los avatares de una vida (memorias de un maestro asturiano) (Gijón: Muséu del Pueblu d'Asturies-Fundación Municipal de Cultura, Educación y Universidad Popular del Ayuntamiento de Gijón, 2009), o Carmen Diego Pérez, Luis Huerta: maestro e higienista (Oviedo: KRK Ediciones, 2006): fueron dos maestros que se declararon católicos siempre, pero prefirieron militar en las asociaciones socialistas. Huerta, además, colaboró con Poveda y dirigió un periódico profesional, La Enseñanza Moderna.

${ }^{62}$ Su aprobación se publicó en la Gaceta del 11 de julio de 1858. Véase B.O.E.O. Sigüenza 106 (22 de agosto de 1863): 256.
} 
regente de la escuela práctica de la Normal de Maestras de Valencia, recomendadas a los maestros de la diócesis ovetense. ${ }^{63}$ La primera, titulada La joven bien educada, publicada en Valencia en 1875, eran unas lecciones de urbanidad para niñas y adultas, aprobada por la autoridad eclesiástica y declarada texto escolar por la Real Orden de 30 de enero de 1879; otra, Nociones de Historia de España, fue publicada en Valencia en 1878, e igualmente aprobada como libro de texto en 7 enero de 1880 , mientras que la tercera, Oraciones en verso para ser pronunciadas a la entrada y la salida de la escuela, careció de autorización estatal.

No fueron muchas las veces que los boletines trataron directamente de los libros escolares utilizables en la enseñanza primaria, pero, por la cantidad de obras y la fama de la editorial, hubo un caso a destacar que fue, según dice el Obispo de Oviedo en septiembre de 1893, objeto de atención en «la prensa periódica, sin distinción de matices políticos», 64 alertando a párrocos y maestros del riesgo de utilizar los libros editados por Saturnino Calleja Fernández (1853-1915). Sus libros, especialmente las obras de su fondo editorial destinadas para ser utilizadas en la enseñanza primaria o como lecturas infantiles, fueron denunciados y de ello se ocuparon durante meses varios boletines. Este editor mantuvo, en la última década del siglo, un enconado enfrentamiento en la prensa en torno a sus libros que fue dilucidado en los tribunales de justicia civiles y eclesiásticos. La llamada de atención de los obispos sobre una parte de los libros de esta editorial parece que partió del Obispo de Plasencia en 1893, y a él se unieron para prohibirlos los obispos de Ciudad Rodrigo, Ávila, Vich, Badajoz, Málaga, Menorca, Orense, Oviedo y los gobernadores eclesiásticos de Santander, Coria y Tarazona. Este enfrentamiento tuvo múltiples actores al implicarse editores, maestros, directores de periódicos, etc., siendo denunciados por Saturnino Calleja varios de ellos ante los tribunales civiles y defendiéndose este en el auto de censura eclesiástica. Este editor ha sido objeto de algunos estudios ${ }^{65}$ que no

\footnotetext{
${ }_{63}$ Véase, entre otros, el B.O.E.O. Oviedo 3 (1 de febrero de 1881): 48.

${ }^{64}$ Circular número 83 del Obispo de Oviedo, el 22 de agosto de 1893 a los Arciprestes y Párrocos, en B.O.E.O. Oviedo 17 (1 de septiembre de 1893): 383.

65 Véase, por ejemplo, Julio Ruiz Berrio (dir.), La editorial Calleja, agente de modernización educativa en la Restauración (Madrid: Universidad Nacional de Educación a Distancia, 2002) o Enrique Fernández de Córdoba Calleja, Saturnino Calleja y su editorial. Los cuentos de Calleja y mucho más (Madrid: Ediciones de la Torre, 2007).
} 
mencionan este enfrentamiento; por tanto, las dimensiones de este conflicto requieren ser estudiadas con mayor detalle pues en él se revelan enfrentamientos entre maestros, sus asociaciones, impresores, autores de libros escolares, etc.

También en los boletines se reproduce el Edicto de 1908 rechazando las teorías contenidas en sendos libros titulados Lo que debe saber el niño y Lo que debe saber la niña de Silvanus Stall y de Mary Word Hallen respectivamente, que habían sido traducidos y publicados en Madrid. El obispo de Barcelona había hecho la consulta a Roma, indicándole la Sagrada Congregación del Índice que no eran convenientes para la enseñanza y que así lo debía comunicar a todos los fieles de lengua española, razón por la que encontramos este texto en varios boletines. ${ }^{66}$

La iniciativa que tomó la Junta Provincial de Instrucción Pública de Barcelona el 14 de mayo de 1912 pidiendo a todas las juntas locales de esa provincia que vigilaran a las escuelas de primera enseñanza no oficial, avisándoles que en ese territorio estaba prohibido utilizar diecinueve libros editados por la Escuela Moderna, pues los «estima perniciosos para que se utilicen como textos en las escuelas de enseñanza primaria», ${ }^{67}$ fue reproducida en varios boletines, en algunos casos a petición de la Junta Central de Acción Católica.

En definitiva, cuando los obispos detectaban libros escolares sospechosos daban la voz de alarma y pedían a párrocos e inspectores que comprobaran durante la visita a las escuelas no solo los de religión y lectura sino también los de otras materias. El control sobre lo que se leía fue una preocupación permanente de la Iglesia católica y llevó a los obispos a enfrentarse al gobierno en dos ocasiones al poner éste en marcha iniciativas bibliotecarias. La primera vez fue contra las bibliotecas populares que, gestionadas por los maestros, se instalaron en las escuelas ${ }^{68}$ desde 1869 y, por segunda vez, contra la iniciativa de la

\footnotetext{
${ }^{66}$ En 1931, la misma Congregación emite un decreto sobre educación sexual y eugenesia.

${ }_{67}$ Es el del B.O.E.O. Menorca (31 de julio de 1912): 155-156; en otros simplemente se reproduce la circular como en el B.O.E.O. Oviedo 17 (1 de agosto de 1912): 237-238.

${ }_{68}$ Véase en el B.O.E.O. Osma 49 (13 de diciembre de 1876): 341-373, el edicto condenando y reprobando obras y pidiendo que los feligreses que tuvieran los ejemplares citados los entregaran al párroco «con la advertencia de que por el hecho mismo incurre en la pena de excomunión» para lo que el obispo mandó que este edicto fuera leído en las parroquias.
} 
Dirección General de Primera Enseñanza que, desde 1912, envió bibliotecas populares circulantes para niños y maestros. ${ }^{69}$

\section{RECAPITULACIÓN}

El haber decidido acudir en primer lugar a los boletines eclesiásticos para conocer el control que la Iglesia católica ejerció sobre el magisterio y los libros utilizados en la enseñanza primaria requirió investigar sobre el origen y evolución de estas publicaciones periódicas, conocer el contexto histórico en el que se desenvolvieron, su carácter oficial para la Iglesia católica y, desde 1862, para el estado. Con la consulta realizada fue posible estimar la variedad de la temática educativa que contienen, y comprobar que estos boletines no sólo fueron un aparato ideológico y de persuasión, el órgano que utilizó la jerarquía eclesiástica como grupo de presión que defendía sus intereses específicos, sino que aportan hechos y acontecimientos educativos merecedores de atención. Estos boletines reflejan no sólo la ya conocida y manifiesta conflictividad coyuntural de la iglesia y el estado, sino también otra latente, estructural, que afectó al magisterio primario, a inspectores de enseñanza y a la educación española en general.

Con los boletines eclesiásticos empezamos a reconstruir una parte de las relaciones que párrocos y maestros debían mantener, y detectamos los contados enfrentamientos entre ambos que acabaron en los tribunales y fueron difundidos y repetidos en estas publicaciones durante varios años cuando las autoridades administrativas resolvieron a favor de la Iglesia católica; no así cuando dieron la razón al maestro.

Consideramos que la consulta de estos boletines es imprescindible para conocer y entender la relación dialéctica entre la Iglesia católica y el estado en España en el ámbito de la educación por influir las decisiones y actuaciones de uno en las del otro. Estas publicaciones recogen el conjunto de las interacciones facilitando que la totalidad de la relación sea comprensible, ayudando a formular explicaciones de orden teórico y de conjunto.

\footnotetext{
69 «Un nuevo avance cauteloso», B.O.E.A. Santiago (15 de octubre de 1913). En esta ocasión atacaron directamente a varios autores (Pérez Galdós, Diderot, Rousseau, Poe, Darwin, Maquiavelo, Descartes...) - anticipando el expurgo de todas las bibliotecas que puso en marcha el franquismo-y el que se incorporaran novelas.
} 
En este sentido, la consulta simultánea de la prensa profesional y de diarios nacionales y locales junto con estos boletines eclesiásticos fuentes digitalizadas actualmente en numerosos casos- permitirá conocer la opinión de los diversos grupos sociales, descubrir las preocupaciones de cada momento, detectar los silencios u ocultaciones, así como contrastar y comparar las versiones de una misma cuestión, en este caso educativa; en definitiva, construir un análisis histórico más sólido.

\section{Nota sobre las autoras}

Carmen Diego Pérez es doctora en Pedagogía por la Universidad de Oviedo (1996), institución en la que inició su actividad docente y en la que continúa como profesora titular en el área de conocimiento Teoría e Historia de la Educación. Su primera línea de investigación se centró en los libros de texto utilizados en la enseñanza primaria española durante el siglo XX y con ella continúa, indagando sobre otros mecanismos de control de la enseñanza primaria utilizados por el estado como los premios y recompensas a maestros y escolares en actos públicos o la depuración de las bibliotecas escolares. Paralelamente ha publicado diversos trabajos sobre la eugenesia y sus conexiones con la educación, la formación del magisterio en educación infantil, el patrimonio histórico-educativo y la alfabetización informacional y gestión de la información sobre educación.

Montserrat González Fernández es profesora titular de la Universidad de Oviedo desde 1999 en el área de Teoría e Historia de la Educación. Premio extraordinario de doctorado en Pedagogía y Premio «Juan Uría Ríu» para trabajos de investigación sobre cultura o historia asturianas en su $18^{\mathrm{a}}$ edición. Su primera línea de investigación fue sobre historia de la educación social, y desde entonces ha profundizado también en la historia de la educación en Asturias y en el patrimonio histórico-educativo, así como en la gestión de la información y en el ámbito de la Pedagogía social. Algunas de sus publicaciones versan sobre: los reconocimientos y recompensas a los maestros, su cualificación profesional o sus actividades de perfeccionamiento; el papel del magisterio en la creación de bibliotecas, en el reconocimiento de premios y honores a 
los escolares o en el uso que hizo de la radio escolar; la colaboración histórica de la Universidad de Oviedo con las fundaciones benéficas, así como la investigación y la formación en Pedagogía Social desarrollada en dicha Universidad o la recopilación y análisis de la historiografía educativa asturiana.

\section{REFERENCIAS}

Bartolomé Martínez, Bernabé (dir.). Historia de la acción educadora de la Iglesia en España. Madrid: Biblioteca de Autores Cristianos, 1997.

Borque, Leonardo y Jesús Suárez López (eds.). Julián Campo Zurita (18911978). Los avatares de una vida (memorias de un maestro asturiano). Gijón: Muséu del Pueblu d’Asturies - Fundación Municipal de Cultura, Educación y Universidad Popular del Ayuntamiento de Gijón, 2009.

Cárcel Ortí, Vicente. «Los Boletines oficiales eclesiásticos de España». Hispania sacra 37, no. 19 (1966): 48-50.

Dávila Balsera, Paulí, Luis M. Naya Garmendía e Hilario Murua Cartón. «Prácticas y actividades religiosas en los colegios privados del País Vasco durante el siglo XX». Historia y Memoria de la Educación 4 (2016): 141-175.

Diego Pérez, Carmen. Luis Huerta: maestro e higienista. Oviedo: KRK Ediciones, 2006.

Fernández de Córdoba Calleja, Enrique. Saturnino Calleja y su editorial. Los cuentos de Calleja y mucho más. Madrid: Ediciones de la Torre, 2007.

García Regidor, Teódulo. La polémica sobre la secularización de la enseñanza en España (1902-1914). Madrid: Fundación Santa María, 1985.

García Regidor, Teódulo. "La actitud de la Iglesia española ante la política educativa del Estado y el fenómeno de la secularización docente. La segunda mitad del siglo XIX y siglo XX». En Historia de la acción educadora de la iglesia en España, dirigida por Bartolomé Martínez, t. II, 137-161. Madrid: Biblioteca de Autores Cristianos, 1997.

Hernández Fuentes, Miguel-Ángel. «"Educar cristianamente a los obreros”. Actividad educativa en la diócesis de Zamora durante la Restauración: las escuelas de adultos y el círculo católico de obreros». Historia de la Educación. Revista Interuniversitaria 36 (2017): 253-256.

Higueruela Pino, Leandro. «En torno a la bibliografía del Boletín Eclesiástico de la diócesis de Toledo en el siglo XIX». Hispania Sacra. Revista de Historia eclesiástica de España 31, no. 61 (1978): 571-667; 34, no. 70 (1982): 551-666; 35 , no. 71 (1983): 317-367; 40, no. 81 (1988): 469-538; 42, no. 85 (1990): 113166; 43, no. 87 (1991): 121-152 y 44, no. 89 (1992): 249-287. 
Marín-Porgueres, Javier. «La recepción en España del Magisterio de Pío XI sobre la Santidad. Un estudio desde los Boletines Eclesiásticos». Cuadernos doctorales: teología (Excerpta e dissertationibus in Sacra Theologia) 60 (2013): 475-563.

Martín Hernández, Francisco. "La actitud del episcopado». En Historia de la educación en España y América. La educación en la España contemporánea (1789-1975), coordinado por Buenaventura Delgado Criado, 560-568. Madrid: Fundación Santamaría-Ediciones SM, 1994.

Martín Zúñiga, Francisco. «La lucha contra la secularización de la enseñanza en las primeras décadas del siglo XX (1900-1930) vista desde el Boletín Oficial del Obispado de Málaga». Puerta Nueva. Revista de Educación 17 (1993): 61-70.

Martorell Pérez, Manuel, Salomó Marquès Sureda y Mª Carmen Agulló Díaz. Pioneras. Historia y compromiso de las hermanas Úriz Pi. Tafalla: Txalaparta, 2018.

Pablo Hervás, Sandra de. «El conflicto de las desamortizaciones en el Boletín Eclesiástico del Obispado de Osma». PhD diss., Universidad Pontificia de Salamanca, 2000.

Palomares, Jesús María. «La economía de la iglesia española. El caso de la diócesis de Osma (1851-1936)». Investigaciones históricas. Época moderna y contemporánea 19 (1999): 103-123.

Paz Velázquez, Flavia. Proyectos pedagógicos. Madrid: Narcea, 1987.

Pazos, Antón M. «El párroco eficaz. Técnica parroquial y mentalidad eclesiástica en la bibliografía recomendada por el Boletín de Pamplona (1900-1930)». Hispania sacra 57, no. 116 (2005): 709-744.

Pazos, Antón M. «Lectura y religión en Navarra: libros sobre espiritualidad difundidos a través del Boletín Oficial Eclesiástico (1900-1930)». Hispania sacra 56, no. 114 (2004): 741-772

Porto Ucha, Ángel Serafín. «La postura de la iglesia gallega ante el tema de la enseñanza a través de los boletines eclesiásticos durante la Restauración». En Iglesia y educación en España. Perspectivas históricas. IV Coloquio de Historia de la Educación. Palma septiembre 1986, t. I, 255-263. Palma de Mallorca: Universitat de les Illes Balears. Sección de Historia de la Educación de la S.E.P., 1986.

Postius y Sala, Juan. La iglesia y la catequesis. Síntesis canónico-legal sobre la enseñanza religiosa en España. Madrid-Barcelona: Corazón de María, 1929.

Poveda, Pedro. Epistolario 1898-1917. Madrid: Narcea, 2012.

Ruiz Berrio, Julio (dir.). La editorial Calleja, agente de modernización educativa en la Restauración. Madrid: Universidad Nacional de Educación a Distancia, 2002.

Salomón Chéliz, Pilar. «Mucho más que religión: Contenidos de la prensa eclesiástica oficial: el Boletín Eclesiástico Oficial del Arzobispado de Zaragoza 
(1900-1936)». En Prensa y periodismo especializado: historia y realidad actual: I congreso de prensa y periodismo especializado, editado por Juan José Fernández Sanz, José Carlos Rueda Laffond y Carlos Sanz Establés, 193208. Guadalajara: Ayuntamiento de Guadalajara, 2002.

Terrón Bañuelos, Aida. "Cien años de defensa colectiva: la dinámica societaria y sindical del Magisterio Español». Sarmiento. Anuario Galego de Historia da Educación 3 (1999): 157-162.

Tuñón de Lara, Manuel. Metodología de la historia social de España. Madrid: Siglo XXI de España, 1973. 